\title{
DNA ploidy and S-phase fraction in carcinoma of the gallbladder related to histopathology, number of gallstones and survival ${ }^{1}$
}

\author{
Ulf Gustafsson ${ }^{\mathrm{a}, *}$, Curt Einarsson ${ }^{\mathrm{b}}$, \\ Lennart C. Eriksson ${ }^{c}$, Virgil Gadaleanu ${ }^{\mathrm{d}}$, \\ Staffan Sahlin ${ }^{\mathrm{a}}$ and Bernhard Tribukait ${ }^{\mathrm{e}}$ \\ ${ }^{a}$ Department of Surgery, Danderyd Hospital, Sweden \\ ${ }^{\mathrm{b}}$ Center for Gastroenterology, Huddinge University \\ Hospital, Sweden \\ ${ }^{\mathrm{c}}$ Department of Pathology, Huddinge University \\ Hospital, Sweden \\ ${ }^{\mathrm{d}}$ Department of Pathology, Malmö University \\ Hospital, Sweden (during the time of the study \\ working at Department of Pathology, Huddinge \\ University Hospital) \\ ${ }^{\mathrm{e}}$ Department of Medical Radiation Biology, \\ Karolinska Hospital, Karolinska Institutet, Stockholm, \\ Sweden
}

Received March 2000

Accepted 21 January 2002

Gallstones are a risk factor for the development of gallbladder cancer. We studied DNA ploidy and cell cycle composition by flow cytometry in archival specimens from 52 gall bladder carcinomas in relation to histopathological grade, tumour stage, gallstone number and survival. $69 \%$ of the gallbladder carcinomas showed aneuploidy. All tumours with single stones $(N=11)$ were aneuploid while only $61 \%$ of tumours with multiple stones $(N=41)$ were aneuploid $(p=0.002)$. DNA aneuploidy was related to increase in Tcategory $(p=0.01)$, grade $(p=0.02)$, and nuclear pleomorphism $(p=0.0005)$. The distribution of DNA ploidy shifted from tetraploid in low stage towards triploid positions in high

\footnotetext{
${ }^{1}$ Presented in part at Digestive Disease Week, annual meeting of the American Gastroenterological Association in New Orleans, Louisiana, USA, May 17-20, 1998.

${ }^{*}$ Corresponding author: Dr. Ulf Gustafsson MD, Department of Surgery, Danderyd Hospital, SE-182 88 Danderyd, Sweden. Tel.: +46 8 6555000; Fax: +46 8 6557766; E-mail: Ulf.Gustafsson@kir. ds.sll.se.
}

stage tumours $(p=0.02)$ combined with higher S-phase values in triploid tumours $(p=0.05)$. S-phase fraction increased during development from normal tissue to dysplasia, cancer in situ and cancer in diploid cases $(p=0.0002)$, and further at the change from diploid to aneuploid $(p=0.004)$. At a median cancer specific survival time of four months patients with diploid tumours had a better survival than those with aneuploid tumours $(p=0.02)$. In multivariate analysis of the tumour characteristic, only T-category and tumour grade were independent prognostic factors.

The shift from diploid to aneuploid and the further shift of ploidy within aneuploid tumours are in agreement with the concept of a clonal development of gallbladder cancer. These changes are combined with a stepwise increase in the fraction of S-phase cells. Low frequency of symptoms in single stone patients may be the reason for detection of malignancy at a late stage of tumour development.

Keywords: Gallbladder cancer, flow cytometry, DNA ploidy, $\mathrm{S}$ phase fraction, cell cycle, gallstone number, survival

\section{Introduction}

Gallstones have for a long period of time been regarded as a major risk factor for the development of gallbladder cancer [11]. This has been confirmed in recent epidemiological studies [42]. Common risk factors have been demonstrated in patients with cholesterol gallstones and gallbladder cancer. These include sex, total calorie intake and body mass index [31,41]. A trend of increasing incidence of gallbladder cancer is observed in Sweden since 1960 [4,22]. This is the background for an ongoing study in the Stockholm County. Part of this study is to investigate the frequency of various lesions, including DNA ploidy and cell cycle composition, in the gallbladder mucosa of gallstone patients with and without tumour disease and gallstonefree subjects. 
Here we investigated DNA ploidy pattern and cell cycle composition in tumours from patients with gallbladder carcinoma and related these tumour characteristics to other morphological and prognostic parameters including number of stones. In the evaluation of DNA ploidy (diploid versus aneuploid) tumour heterogeneity was also studied. Earlier studies on ploidy and cell proliferation in gallbladder cancer have yielded conflicting results with respect to frequency of aneuploidy, size of S-fraction and relationship with morphological, clinical and prognostic factors. Stone number has not been studied in this context before.

\section{Material and methods}

This study includes archival specimens from 52 patients referred to our departments for cholecystectomy between 1986 and 1994 and in which a gallbladder carcinoma was diagnosed. The median age of the patients was 71 years, range 45 to 85 . There were 41 female and 11 male patients. All patients had gallstones. All but four patients with advanced local tumour growth (three with tumour stage pT4 and one pT3) were cholecystectomized. In 14 of the patients the diagnosis of cancer was suspected preoperatively. These patients were operated for gallstone and/or tumour related pain or cholecystitis. In the remaining 38 patients the cancer was diagnosed intra- or postoperatively at the morphological evaluation of the operative specimens. In one patient a secondary operation with wedge resection of liver and extended lymphadenectomy was performed. No patient was subjected to radiation or cytotoxic drug therapy. The ethical aspects of the study were approved by the Ethical Committee of the Karolinska Institute.

\subsection{Cell material}

Depending on the amount of tumour tissue available at the histopathological evaluation of the tissue blocks, 1 to 6 samples from the 52 tumours, with a mean of 2.2 samples/tumour, were excised for DNA analysis. In addition, histopathologically normal mucosa was sampled from 18 patients, dysplasia lesions from 14 and cancer in situ lesions adjacent to invasive tumours from 2 patients. Normal tissue and necrosis was carefully excluded from tumour tissue. Tumour stage was assessed according to the TNM classification of The International Union Against Cancer (UICC) and The American Joint Committee on Cancer (AJCC) after reviewing the patients hospital files [2,3]. The tumours were classified as well, moderately or poorly differentiated according to the WHO classification system and reviewed by one of us (V.G.) [1]. In addition, nuclear pleomorphism were determined and subdivided as weak and strong.

\subsection{DNA flow cytometry}

$100 \mu \mathrm{m}$ thick sections from representative parts of the gallbladder cancer were excised from the formalin fixed and paraffin embedded specimens. The samples were prepared as described earlier [15]. Briefly, each tissue section was put into a bag of nylon mesh, deparaffinized, rehydrogenated and incubated for half an hour at $37^{\circ} \mathrm{C}$ in $1 \mathrm{ml}$ solution of protease $(0.1 \%$ Sigma protease XXIV, 0.1 M Tris buffer, 0.07 M NaCl, $\mathrm{pH}$ 7.2). The suspensions of cell nuclei were stained by directly adding $1.0 \mathrm{ml}$ of DAPI solution (10 $\mu \mathrm{M}$ DAPI in $800 \mu \mathrm{M}$ disodiumhydrogenphosphate). Before measuring the DNA content of the nuclei, the suspensions of cell nuclei were inspected microscopically in order to control the that they were representative of the cell material. Samples were also collected from material representing dysplastic gallbladder mucosa and normal gallbladder tissue when present. DNA content of a mean number of 31,500 cells (range 1200-60000) per histogram was analysed with a PAS II Flow Cytometer (PARTEC, Münster, Germany). For cell cycle analyses, the sliced nuclei option for background subtraction of the Multicycle program (version 3.0, Phoenix Flow Systems, San Diego, CA, USA) was used. DNA histograms with a single peak were classified as diploid. The DNA histograms showing an additional G1 peak were classified as aneuploid. Existence of tetraploidy was assumed to be present if the proportions of cells at $4 c$ exceeded $8 \%$ (mean $+3 \mathrm{SD}$ ) found in normal tissue biopsies and, if in addition, an octoploid G2 peak was present. The level of the DNA-index (DI) was determined in relation to the diploid G1 peak. The existence of several aneuploid cellpopulations was assumed to be present if the DNA-index in two or more samples had a difference of at least $0.1(0.2 \mathrm{c})$ or if within one sample two aneuploid peaks were identified. Tumours in which one sample was diploid and another one was aneuploid were regarded as aneuploid. Poor quality histograms with high background and/or high coefficient of variation $(>8 \%)$ were discarded. Cell cycle analyses was not possible to perform in $14 \%$ of diploid and $33 \%$ of aneuploid cellpopulations due to signal/background ratios (background aggregates and debris, BAD) in the S-phase region of $<1$ [14]. 


\subsection{Statistical analyses}

Data are presented as mean values \pm standard deviation. Statistical analysis were performed using a statistical software package (JMP 3.1, SAS Institute Inc.) Differences were calculated according to Student's $t$-test, Wilcoxon rank sums test or KruskalWallis non parametric test. Disease specific survival was analyzed according to the Kaplan-Meier method and differences in survival distribution were analyzed with the generalised Wilcoxon test. Multivariate survival analysis was made with a parametric log normal model. Endpoint was tumour death. Results with $p<0.05$ were considered statistical significant.

\section{Results}

\subsection{Morphology}

52 tumours were analysed. There were 41 pure adenocarcinomas, 2 adenosquamous carcinomas, 3 mucinous carcinomas, 4 papillary carcinomas and 2 carcinomas in situ. Half of the 52 tumours had an advanced local tumour stage with tumour invading beyond the serosa or into adjacent organs, pT3 or pT4. Twenty patients showed lymph node metastases and 3 distant metastases. Combining local tumour stage with the existence of metastases, 2 patients were of stage 0,11 of stage I, 8 of stage II, 21 of stage III and 10 of stage IV according to the classification of the American Joint Committee of Cancer (AJCC) [2]. One tumour was well differentiated, 26 were moderately and 25 poorly differentiated. 15 of 52 tumours studied showed weak nuclear pleomorphism and 37 strong.

\subsection{DNA ploidy}

36 of the tumours $(69 \%)$ were found to be aneuploid and $16(31 \%)$ diploid. In Table 1, DNA ploidy is depicted in relation to basal clinical and morphological data. The frequency of aneuploidy increased significantly with local tumour stage ( $p=0.01)$, differentiation grade $(p=0.02)$ and nuclear pleomorphism $(p=0.0005)$.

17 cellpopulations from histopathologically normal gallbladder mucosa were diploid and 2 aneuploid/tetraploid (Table 2). Of the 18 cellpopulations found in dysplastic lesions, 10 were diploid and 8 aneuploid. In addition to the 2 primary cancer in situ (CIS), CIS adjacent to invasive tumours were sampled
Table 1

Basal clinical data and DNA ploidy in 52 patients with gallbladder cancer

\begin{tabular}{lrccc}
\hline Variable & \multicolumn{5}{c}{ Patients Diploidy Aneuploidy Dipl. v aneupl. } \\
& $N$ & $N(\%)$ & $N(\%)$ & (Chi-Square) \\
\hline All patients & 52 & $16(31)$ & $36(69)$ & \\
Sex & & & & $p=0.65$ \\
$\quad$ Male & 11 & $4(36)$ & $7(64)$ & \\
Female & 41 & $12(29)$ & $29(71)$ & \\
Tumour (T) stage & 52 & & & $p=0.01$ \\
0 & 2 & $2(100)$ & $0(0)$ & \\
I & 12 & $5(42)$ & $7(58)$ & \\
II & 12 & $5(42)$ & $7(58)$ & \\
III & 18 & $4(22)$ & $14(78)$ & \\
IV & 8 & $0(0)$ & $8(100)$ & \\
Tumour grade & 52 & & & $p=0.02$ \\
$\quad$ Middle or high diff. & 27 & $12(44)$ & $15(56)$ & \\
Low diff. & 25 & $4(16)$ & $21(84)$ & \\
Nucl. pleomorphism & 50 & & & \\
weak & 13 & $9(69)$ & $4(31)$ & \\
strong & 37 & $6(16)$ & $31(84)$ & \\
\hline$N$ & & & & \\
\hline
\end{tabular}

$N=$ number of patients.

from 2 patients. Of the 4 cellpopulations found in the 4 patients, 3 were diploid and 1 aneuploid. 4 cellpopulations found in distant metastases from 2 patients were aneuploid.

\subsection{Distribution of DNA ploidy}

In 152 samples from 52 gallbladder cancers, 89 different cellpopulations were found (Fig. 1). Three different ploidy ranges could be identified. One in the near diploid range between DI 0.8 and DI 1.2, one in the tri/tetraploid range between DI 1.4 and DI 2.0 with maximum around DI 1.7 and scattered cellpopulations with DNA-index exceeding DI 2.1. We subdivided the distribution of DNA-indices in 26 patients with early local tumour stage (Fig. 2) and 26 patients with advanced local tumour stage (Fig. 3). When studying the 33 tumour cellpopulations in the DNA-index range 1.4-2.0, we found a significantly lower mean DNAindex in the 17 cellpopulations with advanced local tumour stage compared to the 16 cell populations with early local tumour stage $(p=0.02)$. Scattered cellpopulations exceeding DNA-index 2.0 were only exceptionally found in the early local tumour stages but were more frequently found in the advanced local tumour stages. Such a shift in ploidy distribution was not seen when comparing high and low grade tumours or tumours with and without lymph node and distant metas- 
Table 2

DNA ploidy, S-phase and G2 fractions, and \% aneuploid cells found in 133 cellpopulations from tumour and adjacent normal tissue of 52 patients with gallbladder cancer

\begin{tabular}{|c|c|c|c|c|c|c|c|}
\hline \multirow[t]{2}{*}{ Histopathology } & \multicolumn{3}{|c|}{ Diploid } & \multicolumn{4}{|c|}{ Aneuploid } \\
\hline & $N$ & S-phase $\%$ & G2\% & $N$ & S-phase $\%$ & $\mathrm{G} 2 \%$ & Aneupl.\% \\
\hline Normal tissue & $\begin{array}{c}17 \\
(15,16)\end{array}$ & $\begin{array}{c}1.6 \pm 1.0 \\
(0.1-3.4)\end{array}$ & $\begin{array}{c}1.7 \pm 2.2 \\
(0.1-8.4)\end{array}$ & $\begin{array}{c}2 \\
(1,2,2)\end{array}$ & 3.4 & $\begin{array}{c}1.0 \pm 1.0 \\
(0.2-1.7)\end{array}$ & $\begin{array}{c}22 \pm 5.7 \\
(18-26)\end{array}$ \\
\hline Dysplasia & $\begin{array}{c}10 \\
(8,9)\end{array}$ & $\begin{array}{c}2.6 \pm 1.7 \\
(0.2-5.6)\end{array}$ & $\begin{array}{c}1.9 \pm 1.3 \\
(0.5-4.7)\end{array}$ & $\begin{array}{c}8 \\
(2,0,8)\end{array}$ & $\begin{array}{c}6.3 \\
(6.3-6.3)\end{array}$ & - & $\begin{array}{c}6.8 \pm 4.8 \\
(2-17)\end{array}$ \\
\hline Cancer in situ & $\begin{array}{c}3 \\
(3,3)\end{array}$ & $\begin{array}{c}4.1 \pm 0.5 \\
(3.7-4.7)\end{array}$ & $\begin{array}{c}5.2 \pm 3.6 \\
(2.6-9.3)\end{array}$ & 1 & 19 & 2.7 & 41 \\
\hline Cancer & $\begin{array}{c}27 \\
(23,23)\end{array}$ & $\begin{array}{c}5.0 \pm 3.0 \\
(0-11.7)\end{array}$ & $\begin{array}{c}4.9 \pm 4.7 \\
(0.5-22)\end{array}$ & $\begin{array}{c}60 \\
(33,37,57)\end{array}$ & $\begin{array}{c}8.6 \pm 5.0 \\
(1-21.3)\end{array}$ & $\begin{array}{c}6.9 \pm 5.9 \\
(1-32.3)\end{array}$ & $\begin{array}{c}25.1 \pm 17.6 \\
(3-78)\end{array}$ \\
\hline Metastases & 0 & & & $\begin{array}{c}4 \\
(3,4,4)\end{array}$ & $\begin{array}{l}15.3 \pm 7.1 \\
(8.2-22.3)\end{array}$ & $\begin{array}{c}4.5 \pm 2.6 \\
(1.2-7.4)\end{array}$ & $\begin{array}{c}44.8 \pm 29.2 \\
\quad(13-72)\end{array}$ \\
\hline
\end{tabular}

Mean values \pm SD. $N=$ number of cell populations found. Number of analyzed cellpopulations in brackets and italic text, in the order: S-phase $\%, \mathrm{G} 2 \%$ and (when present) $\%$ aneuploid cells. Range of S-phase $\%$, G2\% and \% aneuploid cells in brackets.

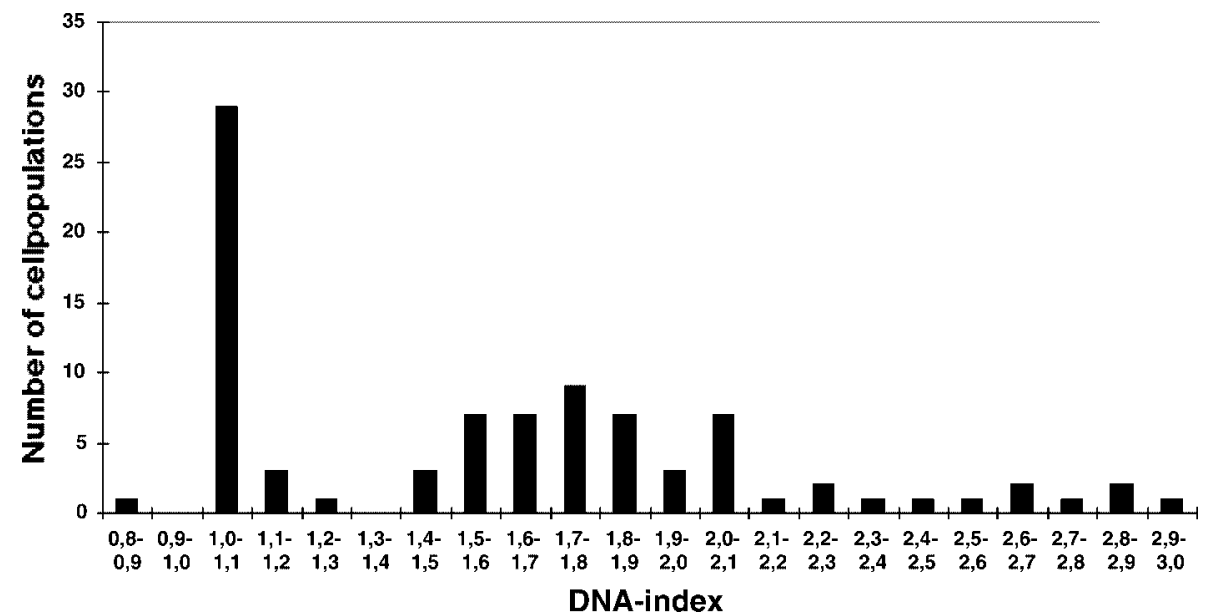

Fig. 1. Distribution of DNA-indices in 89 cellpopulations from 52 patients with gallbladder cancer.

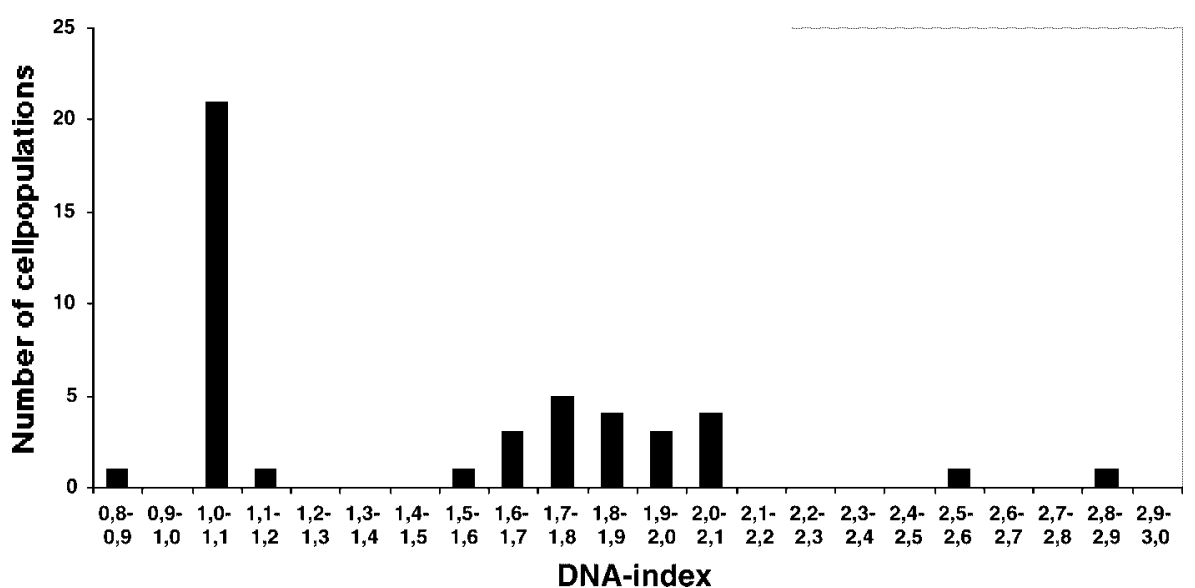

Fig. 2. Distribution of DNA-indices in 45 cellpopulations from 26 patients with gallbladder cancer of early local tumour stage (T0-T2). 


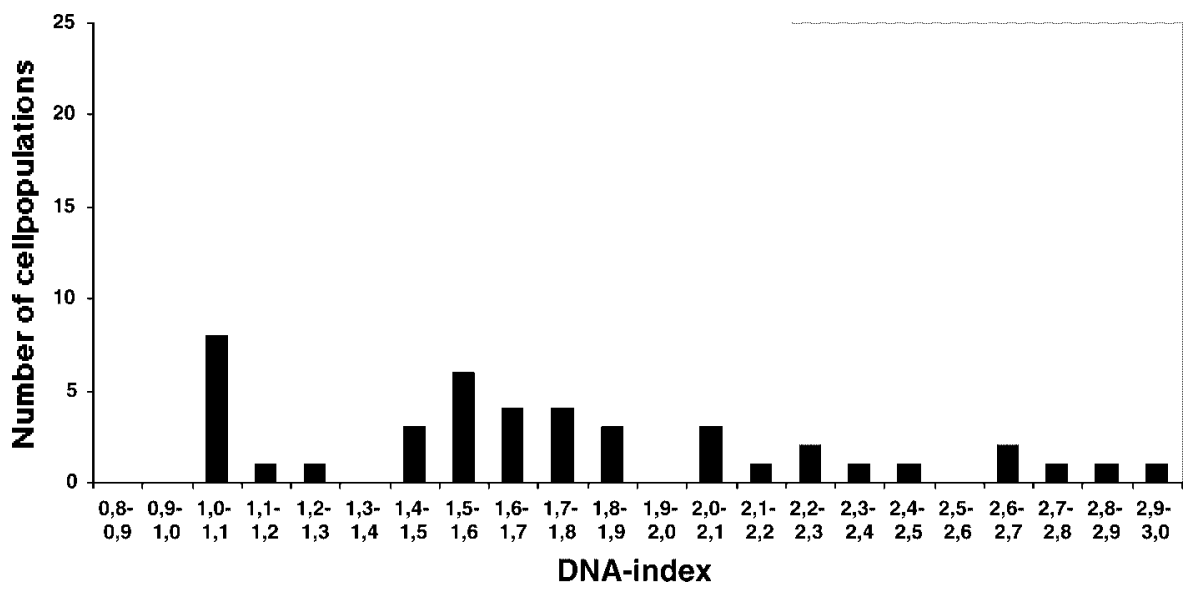

Fig. 3. Distribution of DNA-indices in 43 cellpopulations from 26 patients with gallbladder cancer of advanced local tumour stage (T3-T4).

tases. Among the 31 cellpopulations from 13 tumours with weak or moderate nuclear pleomorphism the few aneuploid cellpopulations were in the near diploid or tetraploid range.

\subsection{Cell cycle composition related to histopathology and DNA ploidy}

A total of 132 cell populations were identified when studying all samples from the various normal and abnormal tissues. The S-phase and G2 fractions in diploid and aneuploid cellpopulations in relation to histopathology are summarised in Table 2. The proportion of S-phase cells in diploid cellpopulations increased from $1.6 \pm 1.0 \%$ in normal tissue to $2.6 \pm 1.7 \%$ in dysplasia, $4.1 \pm 0.5 \%$ in CIS and $5.0 \pm 3.0 \%$ in gallbladder cancer tumour $(p=0.0002)$. S-phase fraction increased further from $5.0 \pm 3.0 \%$ in the diploid tumours, to $8.6 \pm 5.0 \%$ in the aneuploid tumours $(p=0.004)$. The proportion of G2 cells in the diploid cellpopulations also increased significantly from $1.7 \pm 2.2 \%$ in normal tissue to $1.9 \pm 1.3 \%$ in dysplasia, $5.2 \pm 3.6 \%$ in CIS and $4.9 \pm 4.7 \%$ in gallbladder cancer $(p=0.003)$. The mean S-phase fraction from the four aneuploid cellpopulations of the metastases was $15.3 \pm 7.1 \%$. The proportion of aneuploid cells in the aneuploid cellpopulations was $25 \%$ in primary tumours, $45 \%$ in metastases, $7 \%$ in dysplasia and $22 \%$ in the two samples with normal tissue according to histopathology. The number of aneuploid cellpopulations found in non primary tumour tissues were few and the cell cycle composition of these was not eligible for statistical analysis.

When comparing S-phase of aneuploid tumour cellpopulations in the triploid interval $1.3>\mathrm{DI} \leqslant 1.7$ and the near tetraploid interval $1.7>$ DI $<2$ we found significantly higher mean S-phase values in the triploid range $(9.9 \pm 3.9 \%)$, compared to the near tetraploid range $(4.9 \pm 3.8 \%)(p=0.05)$.

The S-phase fraction in poorly differentiated tumours $8.7 \pm 5.1 \%$ was significantly higher than that of the well and moderately differentiated tumours, $5.1 \pm 3.6 \%(p=0.02)$. S-phase fraction in tumours from women was $7.1 \pm 4.6 \%$ and in men $4.5 \pm 3.7 \%$, a non-significant difference $(p=0.06)$.

\subsection{Number of gallbladder stones in relation to DNA ploidy and clinical parameters}

Among the 52 patients with gallbladder cancer, 41 had multiple stones and 11 single stones (Table 3). When studying the existence of multiple and single stones respectively, in relation to clinical parameters and tumour ploidy we found only aneuploid tumours in the 11 cases with single stones. In contrast, of the 41 cases with multiple stones, 25 were aneuploid and 16 diploid. This difference was highly significant ( $p=$ 0.002). The mean S-phase fraction of the cases with single and multiple stones, $8.9 \pm 4.0 \%$ and $5.9 \pm 4.5 \%$, respectively, differed also significantly $(p=0.05)$. This difference however, was due to the lower S-phase values of diploid tumours and disappeared when only the 25 aneuploid tumours of the cases with multiple stones were taken into account $(8.0 \pm 4.9 \%)$. None of the other clinical or morphological characteristics in these two groups of patients showed any differences. 
Table 3

Stone number related to sex, age, T-classification, grade, nuclear pleomorphism, DNA ploidy and S-phase

\begin{tabular}{lccc}
\hline & Multiple & Single & $p$ value \\
\hline$N$ & 41 & 11 & n.s. \\
Sex (male/female) & $8 / 33$ & $3 / 8$ & n.s. \\
Age & $69.2 \pm 9.7$ & $68.5 \pm 12.6$ & n.s. \\
Local tumour stage(T0-T2+/T3-T4) & $21 / 20$ & $5 / 6$ & n.s. \\
Grade (well-moderately/poor) & $20 / 21$ & $7 / 4$ & n.s. \\
Nucl pleomorph (weak/strong) & $12 / 28$ & $1 / 9$ & n.s. \\
DNA-ploidy (diploid/aneuploid) & $16 / 25$ & $0 / 11$ & $P=0.002$ \\
S-phase\% & $5.9 \pm 4.5$ & $8.9 \pm 4.0$ & $P=0.05$ \\
Survival in months & $20.8 \pm 34.6$ & $16.5 \pm 29.4$ & n.s. \\
Number of tumour samples & $2.1 \pm 1.1$ & $2.5 \pm 1.8$ & n.s \\
\hline
\end{tabular}

Mean values $\pm \mathrm{SD} . N=$ number of patients. n.s. $=$ non significant.

\subsection{Survival analysis}

The median overall survival time among the 52 patients was 6.3 months, range $0.3-139$ months. 45 patients died of the gallbladder cancer, with a median survival time of 4 months. Of the remaining seven patients, one died after 128 months of a non-cancer related disease and the other six are still alive after a median observation time of 99 months. Two of these seven long-time survivors had stage 0 disease, four had stage I disease, one had stage II disease. The 16 patients with diploid tumours showed significantly better cancer specific survival than the 36 patients with aneuploid tumours $(p=0.02)$ (Fig. 4(a)). This can be compared with survival in relation to differentiation grade (Fig. 4(b)), nuclear pleomorphism (Fig. 4(c)) and T category according to the TNM system [1] (Fig. 4(d)). S-phase fraction was not significantly related to survival, taking the median value of all $\mathrm{S}$-phase values as cut-off value. In multivariate analysis of the four above mentioned tumour characteristics, T-category was the dominant independent prognostic factor $\left(\chi^{2}=11.4 ; p=0.0007\right)$, followed by tumour grade $\left(\chi^{2}=4.3 ; p=0.04\right)$. DNA-ploidy and nuclear pleomorphism did not reach significance.

\section{Discussion}

The present study is part of an investigation on gallstones as a risk factor for the development of gallbladder cancer $[11,21]$. The aim was to establish the role of DNA measurements in relation to clinical and morphological parameters, particularly number of gallstones, in patients with gallbladder cancer, as the basis for further studies of premalignant or non-invasive lesions of the gallbladder mucosa in patients with and without gallstones. Number of gallstones is of importance in cholesterol gallstone disease $[18,19,29]$ and has not been studied in relation to DNA measurements in gallbladder cancer patients previously.

The results from previous DNA cytometric studies together with those of the present study are summarised in Table 4. The proportion of aneuploid tumours in previous studies varied from $30 \%$ up to $100 \%$. When only considering studies from the literature with a patient number exceeding 40 , the mean proportion of aneuploid tumours, in a total number of 364 tumours studied, was $67 \%$, similar to $69 \%$ in our study. At the evaluation of the proportion of diploid and aneuploid tumours, tumour heterogeneity with the coexistence of diploid in one and aneuploidy in another part of the individual tumour can be the reasons for underestimating the real proportion of aneuploid tumours. In order to evaluate the risk of misclassifying aneuploid tumours as diploid, we also calculated the probability of aneuploidy considering only tumours in which more than 1 biopsy were available for analyses, taking bias of ascertainment into account [38]. At a mean number of 2.9 biopsies per tumour the calculated probability of aneuploidy was $70 \%$ in good accordance with the frequency of $69 \%$ found at the primary evaluation of our data.

Thus, in spite of a high level of intratumoural DNA heterogeneity the risk of misclassifying ploidy status of a tumour in our study seems insignificant and justifies comparisons between the aneuploid and diploid tumours. This justification is further strengthened by the correlations between the proportion of tumour aneuploidy with stage, grade, nuclear pleomorphism and survival in our material. 




(a)

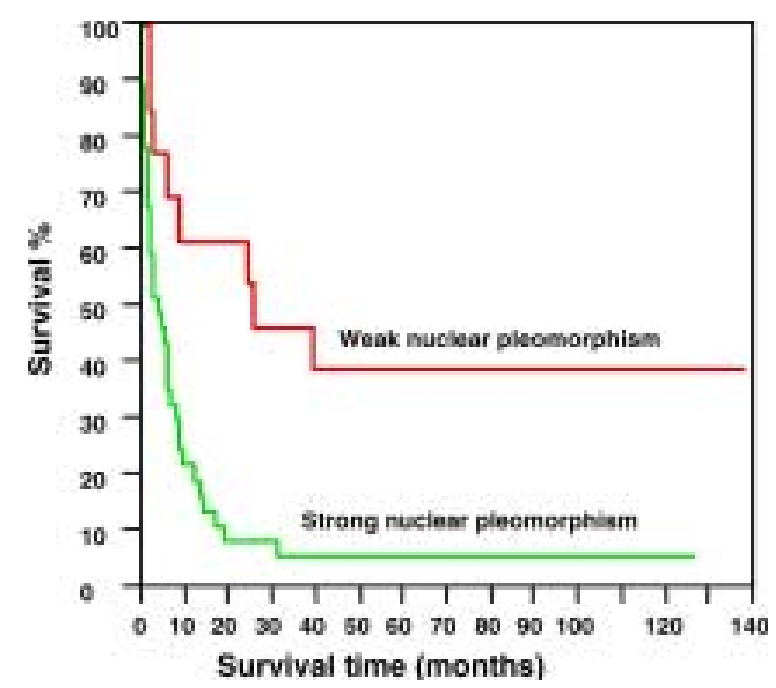

(c)

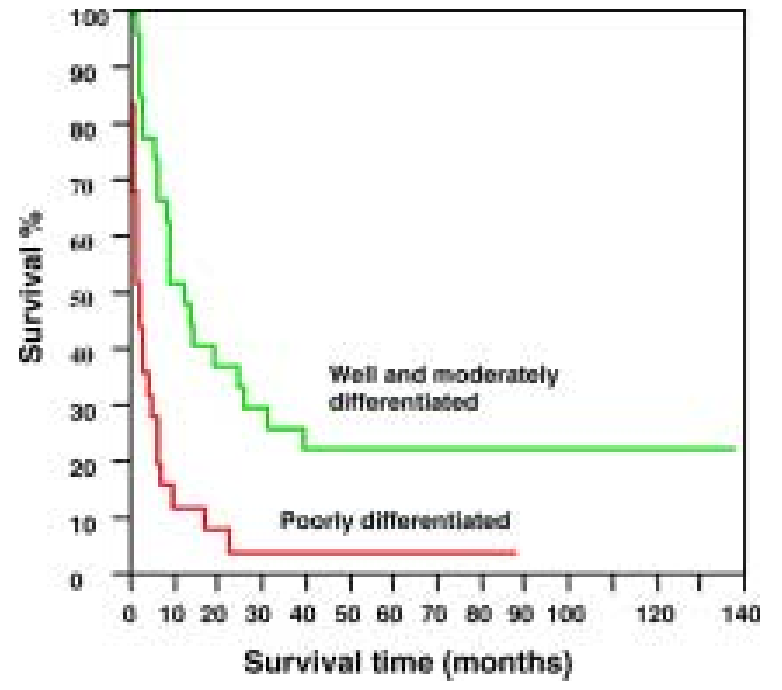

(b)

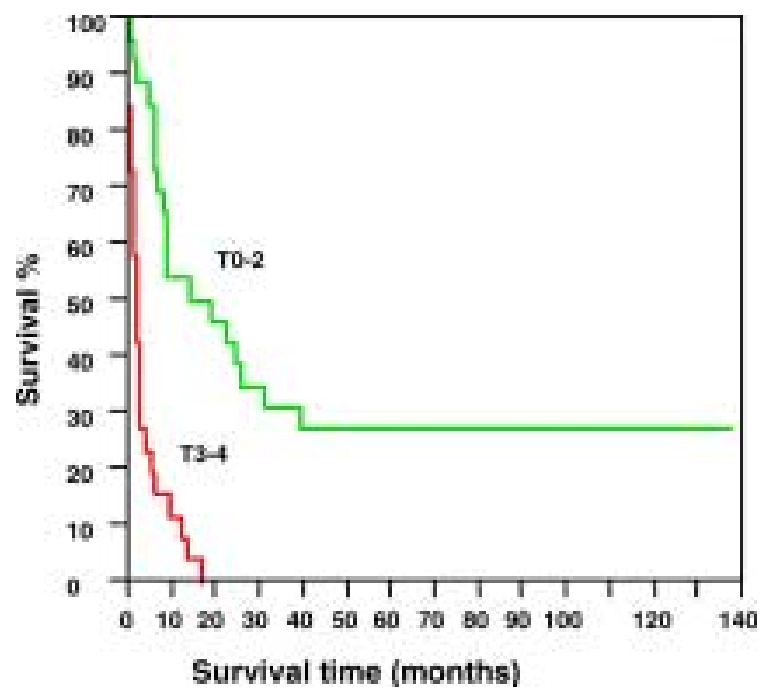

(d)

Fig. 4. (a) Tumour specific survival curves for patients in 36 aneuploid tumours and 16 diploid tumours $(p=0.02$ ). (b) Tumour specific survival curves for patients in 25 poorly and 27 well and moderately differentiated tumours $(p=0.0001)$. (c) Tumour specific survival curves for patients in 13 tumours with weak and 37 with strong nuclear pleomorphism $(p=0.004)$. (d) Tumour specific survival curves for patients in 26 tumours with T classification T0-2 and 26 with T3-4 ( $p<0.0001)$.

An increase in the proportion of aneuploid tumours with T stage (Table 1) supports the concept of a change from diploid to aneuploid DNA patterns in course of tumour development. This concept is further supported by our observation of the coexistence of diploid and aneuploid tumour biopsies in the same tumour, also described by Nishizawa et al. [24].

The distribution of the DNA indices of the tumours with diploid, near diploid positions, triploid- tetraploid positions and those exceeding tetraploidy is in agree- ment with other solid tumours from other sites, such as; colon- rectum, breast, cervix and corpus uteri, and bladder $[5,32,35]$. The positions of the DNA indices in the triploid- tetraploid region correspond to a lin$\log$ normal distribution described also in other solid tumours [32].

A new observation is the shift of the DNA indices from a more tetraploid to a more triploid position with increase of local tumour stage (Figs 2, 3). Combined with a significant increase in the proportion of S-phase 
Table 4

Data of 15 studies of DNA flow cytometry from tumour tissue in gallbladder cancer patients

\begin{tabular}{|c|c|c|c|c|c|}
\hline Study & $N$ & $\begin{array}{c}\text { Aneuploidy } \\
\%\end{array}$ & $\begin{array}{c}\text { S-phase } \\
\%\end{array}$ & $\begin{array}{c}\text { Ploidy related } \\
\text { to survival }\end{array}$ & Comment \\
\hline Koyama, 1984 & 26 & 92 & - & - & ICM \\
\hline Strom, 1989 & 23 & 30 & 9.2 & - & including 3 CIS patients, FCM \\
\hline Donohue, 1990 & 70 & 89 & - & No & $\mathrm{FCM}$ \\
\hline Yamamoto, 1990 & 54 & 46 & - & No & $\mathrm{FCM}$ \\
\hline Suto, 1993 & 8 & 87.5 & - & - & FCM \\
\hline Sato, 1993 & 36 & 56 & - & Yes & $\mathrm{FCM}$ \\
\hline Roa, 1993 & 79 & 44 & - & - & FCM \\
\hline Baretton, 1994 & 48 & 90 & - & No & FCM \\
\hline Ajiki, 1996 & 20 & 80 & - & - & subserosal tumours, some autopsy cases, FCM \\
\hline Nishihara, 1994 & 9 & 78 & - & - & only adenosquamos cases, FCM \\
\hline Nishizawa-Takano, 1996 & 60 & 90 & - & - & FCM \\
\hline Yoshida, 1996 & 18 & 100 & 11.6 & - & FCM \\
\hline Roa, 1997 & 53 & 45 & - & - & ICM \\
\hline Futakawa, 1997 & 12 & 100 & - & - & all autopsy cases, ICM \\
\hline Present study & 52 & 69 & Dipl.: 4.3 Aneupl.: 7.9 & Yes & including 2 CIS patients, FCM \\
\hline
\end{tabular}

$N=$ number, ICM = image cytometry, FCM = flow cytometry.

cells, these changes in positions was also found in bladder carcinoma [33]. From the point of view of tumour development, a shift in ploidy from tetraploid towards triploid positions can be explained by the successive loss of chromosomes combined with loss of suppressor genes involved in cell cycle regulation and resulting in cell populations with advantage of growth.

The difference in the proportion of S-phase cells between diploid and aneuploid tumours found in this series is in accordance with the results of tumours from other sites $[13,34,35]$. We found a successive increase in the proportion of S-phase cells in diploid cell populations at the shift from histopathologically normal tissue to dysplastic lesions and cancers. This and the further increase in the S-phase fraction at the shift from minor to gross chromosomal aberrations underline the role of proliferation in tumour development.

The increase of the size of the S-phase fraction with stage and grade is in accordance with corresponding change of the mitotic index and the AgNOR counts found by others $[24,30]$.

To our knowledge, stone number in relation to tumour characteristics of gallbladder cancer has not been previously studied. All tumours from patients with single stones but only $61 \%$ of those with multiple stones in this study were aneuploid. The proportion of single stones in our study (21\%) is in agreement with an early study encompassing 43 gallbladder cancer patients and other studies regarding cholesterol gallstone patients $[18,19,29]$. Recently described differences in patients with single and multiple cholesterol gallstone patients can be discussed as reasons for this finding. Patients with multiple gallbladder stones have a shorter nucleation time and higher biliary concentrations of total protein and glycoprotein than solitary stones [37]. The stone cholesterol content is higher in solitary stones compared to multiple stones [19]. From the clinical point of view, patients with multiple stones have been associated with more frequent biliary pain and complications such as cholecystitis, cholangitis and pancreatitis $[19,29]$. Considering the lower frequency of clinical symptoms in gallstone patients with single stones, one could expect that patients with single stones harbour their stones for a longer period of time before surgery. When cancer has been established in the gallbladder, the paucity of symptoms related to gallstones in the single stone group, could lead to an operation later in the course of cancer development and thus a longer time for DNA aneuploidy to appear. However, there were no differences in age, local tumour stage or other morphological tumour characteristics between single and multiple stone patients in the present study.

The survival rate in gallbladder cancer patients is still very low and the survival time short despite advancements in the diagnostic procedures and in the clinical care of the operated patients $[7-10,12,16,17$, $20,23,25-28,36,39]$. In three of four earlier studies there has been no relation between ploidy pattern and survival in gallbladder cancer $[6,12,30,40]$. 
In the present study long term survivors existed only among those patients with tumour stage 0-II according to AJCC [2]. Poor survival was related to strong nuclear pleomorphism, low tumour differentiation and DNA aneuploidy. The interpretation of DNA aneuploidy as a process with the appearance of phenotypically more malignant cell populations and accumulated DNA damage during tumour development corresponds to the poor survival of aneuploid patients.

\section{Acknowledgements}

The investigation was supported by grants from the Swedish Medical Society (Bengt Ihre's Fund), the Swedish Medical Research Council (03X-4793 and 03X-7890) and King Gustav V's Jubilee Foundation.

\section{References}

[1] World Health Organization, International Histological Classification of Tumours, World Health Organization, Geneva, 1969-1981, 2nd edn, Springer-Verlag, Berlin, 1988-present.

[2] American Joint Committe of Cancer, in: American Joint Committe of Cancer Staging Manual, I. Fleming, J. Cooper, D. Henson, R. Hutter, B. Kennedy, G. Murphy et al., eds, 5th edn, JB Lippincott, Philadelphia, 1997.

[3] UICC International Union Against Cancer, in: TNM Classification of Malignant Tumors, L. Sobin and C. Wittekind, eds, 5th edn, John Wiley \& Sons, Inc., New York, 1997, pp. 78-80.

[4] J. Ahlberg, L.O. Bergstrand and S. Sahlin, Changes in gallstone morbidity in a community with decreasing frequency of cholecystectomies. A statistical study of the county of Stockholm, Sweden, 1969-1982, Acta Chirurgica Scandinavica - Supplementum 520 (1984), 53-58.

[5] N.B. Atkin and R. Kay, Prognostic significance of modal DNA value and other factors in malignant tumours, based on 1465 cases, Br. J. Cancer 40 (1979), 210-221.

[6] G. Baretton, S. Blasenbreu, T. Vogt, U. Lohrs, H. Rau and M. Schmidt, DNA ploidy in carcinoma of the gallbladder. Prognostic significance and comparison of flow and image cytometry on archival tumor material, Pathol. Res. Pract. 190 (1994), 584-592.

[7] D.L. Bartlett, Y. Fong, J.G. Fortner, M.F. Brennan and L.H. Blumgart, Long-term results after resection for gallbladder cancer. Implications for staging and management, Ann. Surg. 224 (1996), 639-646.

[8] T.C. Chao, C.S. Wang, L.B. Jeng, Y.Y. Jan and M.F. Chen, Primary carcinoma of the gallbladder in Taiwan, J. Surg. Oncol. 61 (1996), 49-55.

[9] K. Chijiiwa, K. Yamaguchi and M. Tanaka, Clinicopathologic differences between long-term and short-term postoperative survivors with advanced gallbladder carcinoma, World J. Surg. 21 (1997), 98-102.
[10] X.A. de Aretxabala, I.S. Roa, L.A. Burgos, J.C. Araya, M.A. Villaseca and J.A. Silva, Curative resection in potentially resectable tumours of the gallbladder, European Journal of Surgery 163 (1997), 419-426.

[11] A.K. Diehl, Epidemiology of gallbladder cancer: a synthesis of recent data, Journal of the National Cancer Institute 65 (1980), 1209-1214.

[12] J.H. Donohue, D.M. Nagorney, C.S. Grant, K. Tsushima, D.M. Ilstrup and M.A. Adson, Carcinoma of the gallbladder. Does radical resection improve outcome?, Arch. Surg. 125 (1990), 237-241.

[13] M.J. Eskelinen, P. Pajarinen, Y. Collan, E. Pesonen, E. Alhava, K. Kettunen et al., Relationship between DNA ploidy and survival in patients with primary breast cancer, Br. J. Surg. 76 (1989), 830-834.

[14] T. Heiden, G. Auer and B. Tribukait, Reliability of DNA cytometric S-phase analysis in surgical biopsies: assessment of systematic and sampling errors and comparison between results obtained by image and flow cytometry, Cytometry 42 (2000), 196-208.

[15] T. Heiden, N. Wang and B. Tribukait, An improved Hedley method for preparation of paraffin-embedded tissues for flow cytometric analysis of ploidy and S-phase, Cytometry 12 (1991), 614-621.

[16] D.E. Henson, J. Albores-Saavedra and D. Corle, Carcinoma of the gallbladder. Histologic types, stage of disease, grade, and survival rates, Cancer 70 (1992), 1493-1497.

[17] P.E. Jonsson and B.A. Pettersson, Carcinoma of the gallbladder - a natural history type of study, J. Surg. Oncol. 21 (1982), 215-218.

[18] D. Jungst, T. Lang, C. von Ritter, E. Pratschke and G. Paumgartner, Cholesterol nucleation time in gallbladder bile of patients with solitary or multiple cholesterol gallstones, Hepatology 15 (1992), 804-808.

[19] T. Juvonen, O. Niemela, J. Makela and M.I. Kairaluoma, Characteristics of symptomatic gallbladder disease in patients with either solitary or multiple cholesterol gallstones, Hepatogastroenterology 41 (1994), 263-266.

[20] V.K. Kapoor and I.S. Benjamin, Resectional surgery for gallbladder cancer, Br. J. Surg. 85 (1998), 145-146.

[21] A.B. Lowenfels, C.G. Lindstrom, M.J. Conway and P.R. Hastings, Gallstones and risk of gallbladder cancer, J. Natl. Cancer Inst. 75 (1985), 77-80.

[22] O. Muhrbeck, S. Sahlin and J. Ahlberg, Rise and fall in the number of cholecystectomies: Stockholm 1932-1993, European Journal of Surgery 162 (1996), 199-204.

[23] L.H. Nadler and C.K. McSherry, Carcinoma of the gallbladder: review of the literature and report on 56 cases at the Beth Israel Medical Center, Mt. Sinai J. Med. 59 (1992), 47-52.

[24] J.E. Nishizawa Takano, H. Ayabe, K. Hatano, H. Yamaguchi and Y. Tagawa, Gallbladder cancer. A comparative study among clinicopathologic features, AgNORs, and DNA content analysis, Dig. Dis. Sci. 41 (1996), 840-847.

[25] K. Ouchi, M. Suzuki, S. Saijo, K. Ito and S. Matsuno, Do recent advances in diagnosis and operative management improve the outcome of gallbladder carcinoma?, Surgery 113 (1993), 324329. 
[26] K. Ouchi, M. Suzuki, T. Tominaga, S. Saijo and S. Matsuno, Survival after surgery for cancer of the gallbladder, British Journal of Surgery 81 (1994), 1655-1657.

[27] H. Paimela, A. Karppinen, K. Hockerstedt, V. Perhoniemi, E. Vaittinen and E. Kivilaakso, Poor prognosis of gallbladder cancer persists regardless of improved diagnostic methods. Incidence and results of surgery during 20 years in Helsinki, Ann. Chir. Gynaecol. 86 (1997), 13-17.

[28] R. Pradeep, S.P. Kaushik, S.S. Sikora, B.N. Bhattacharya, C.M. Pandey and V.K. Kapoor, Predictors of survival in patients with carcinoma of the gallbladder, Cancer 76 (1995), 1145-1149.

[29] E. Ros, R. Valderrama, C. Bru, L. Bianchi and J. Teres, Symptomatic versus silent gallstones. Radiographic features and eligibility for nonsurgical treatment, Dig. Dis. Sci. 39 (1994), 1697-1703.

[30] Y. Sato, J. Tanaka, K. Koyama, T.M. van Gulik, N.J. Lygidakis and M.N. van der Heyde, Tumor DNA content in gallbladder carcinoma, Hepatogastroenterology 40 (1993), 375-379.

[31] B.L. Strom, R.D. Soloway, J.L. Rios-Dalenz, H.A. RodriguezMartinez, S.L. West, J.L. Kinman et al., Risk factors for gallbladder cancer. An international collaborative case-control study, Cancer 76 (1995), 1747-1756.

[32] B. Tribukait, Clinical DNA flow cytometry, Med. Oncol. Tumor Pharmacother. 1 (1984), 211-218.

[33] B. Tribukait, Flow cytometry in assessing the clinical aggressiveness of genito-urinay neoplasms, World J. Urol. 5 (1987), $108-122$.

[34] B. Tribukait, H. Gustafson and P.L. Esposti, The significance of ploidy and proliferation in the clinical and biological evaluation of bladder tumours: a study of 100 untreated cases, Br. J. Urol. 54 (1982), 130-135.
[35] B. Tribukait, C. Hammarberg and C. Rubio, Ploidy and proliferation patterns in colo-rectal adenocarcinomas related to Dukes' classification and to histopathological differentiation. A flow-cytometric DNA study, Acta Pathol. Microbiol. Immunol. Scand. [A] 91 (1983), 89-95.

[36] K. Tsukada, K. Hatakeyama, I. Kurosaki, K. Uchida, Y. Shirai, T. Muto et al., Outcome of radical surgery for carcinoma of the gallbladder according to the TNM stage, Surgery 120 (1996), 816-821.

[37] J. Tudyka, W. Kratzer, K. Kuhn, R. Mason, J.G. Wechsler and G. Adler, Solitary versus multiple gallstones: the importance of total biliary protein concentration and other factors, Hepatogastroenterology 42 (1995), 638-644.

[38] F. Vogel and A.G. Motulsky, in: Human Genetics, Problems and Approaches, Springer-Verlag, Berlin, Heidelberg, New York, 1982, pp. 556-568.

[39] K. Yamaguchi, K. Chijiiwa, S. Saiki, K. Nishihara, M. Takashima, K. Kawakami et al., Retrospective analysis of 70 operations for gallbladder carcinoma, Br. J. Surg. 84 (1997), 200-204.

[40] M. Yamamoto, N. Oda and E. Tahara, DNA ploidy patterns in gallbladder adenocarcinoma, Jpn. J. Clin. Oncol. 20 (1990), 83-86.

[41] W.A. Zatonski, C. La Vecchia, K. Przewozniak, P. Maisonneuve, A.B. Lowenfels and P. Boyle, Risk factors for gallbladder cancer: a Polish case-control study, Int. J. Cancer $\mathbf{5 1}$ (1992), 707-711.

[42] W.A. Zatonski, A.B. Lowenfels, P. Boyle, P. Maisonneuve, H.B. Bueno de Mesquita, P. Ghadirian et al., Epidemiologic aspects of gallbladder cancer: a case-control study of the SEARCH Program of the International Agency for Research on Cancer, J. Natl. Cancer Inst. 89 (1997), 1132-1138. 


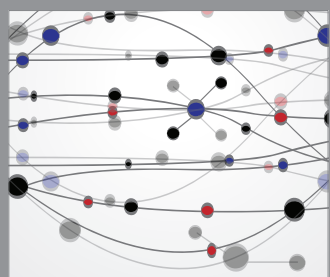

The Scientific World Journal
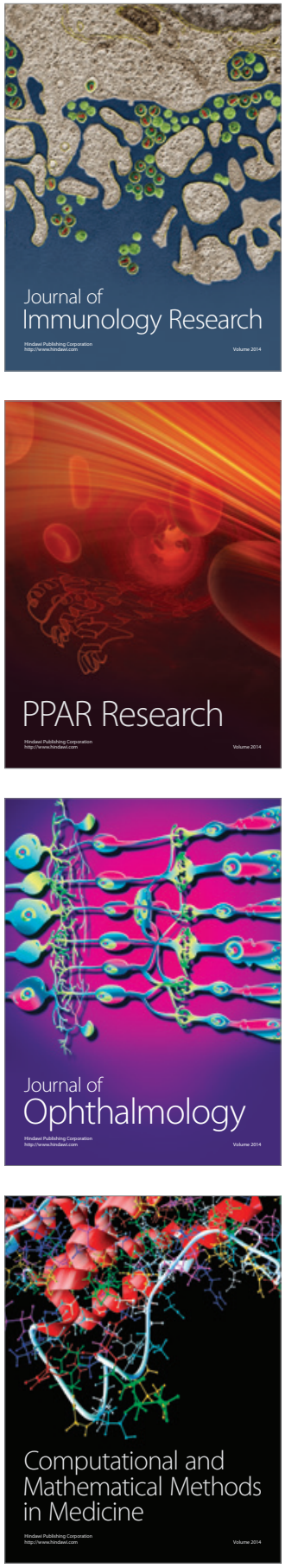

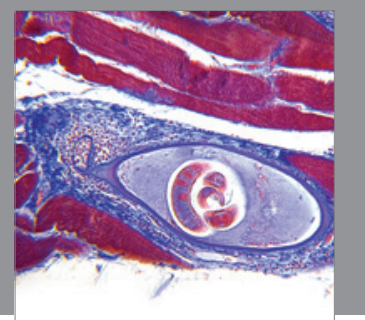

Gastroenterology

Research and Practice
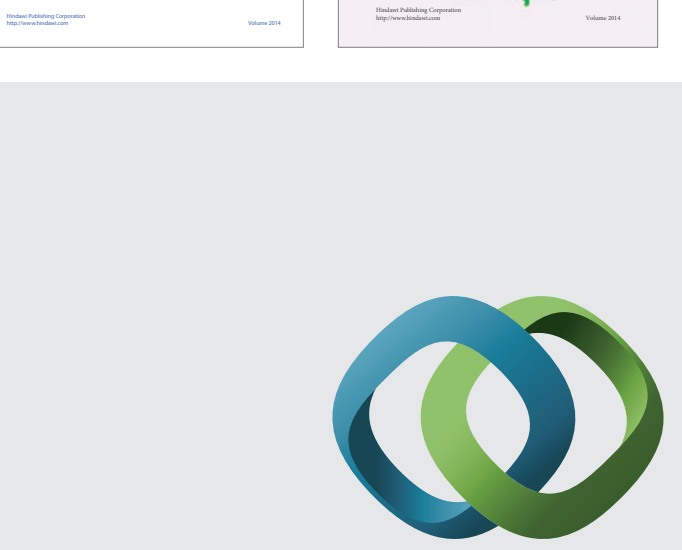

\section{Hindawi}

Submit your manuscripts at

http://www.hindawi.com
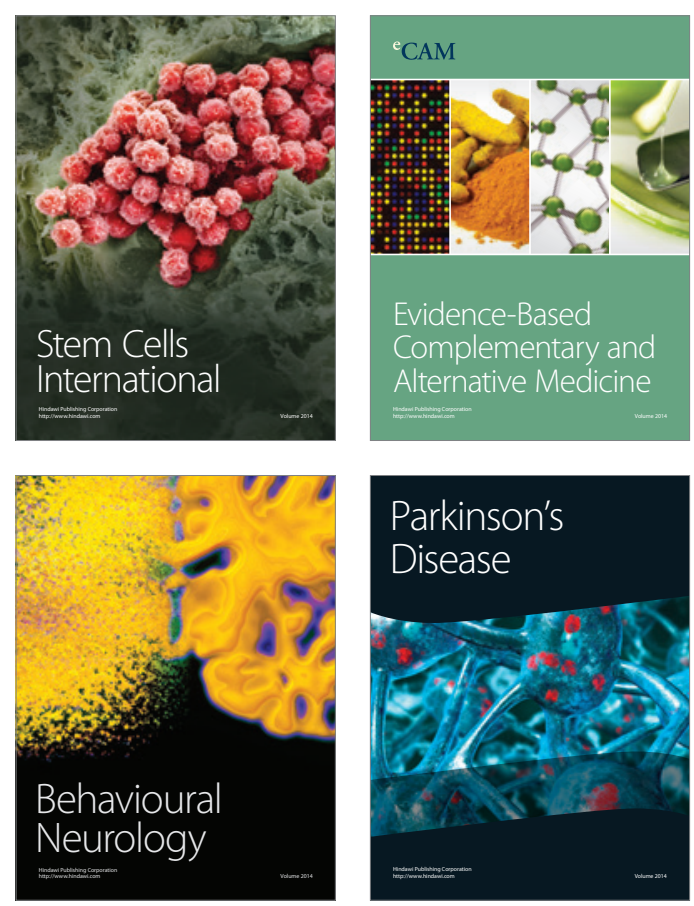

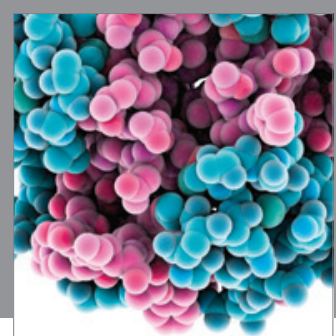

Journal of
Diabetes Research



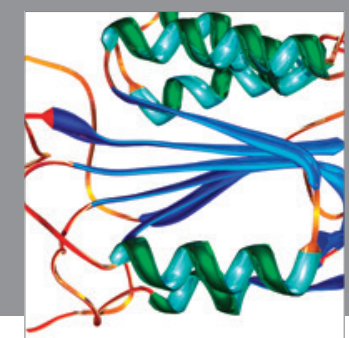

Disease Markers
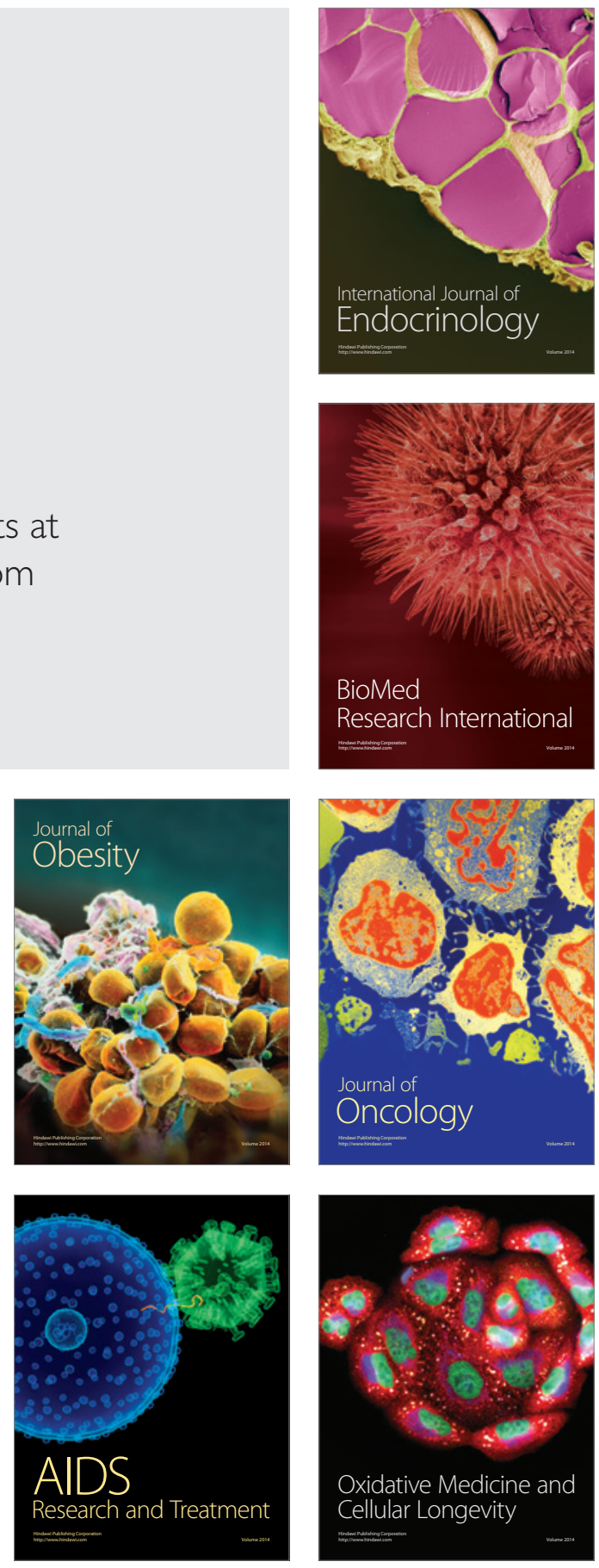